\title{
Corrosion Inhibition Potential of Ethanol Extract of Acacia nilotica Leaves on Mild Steel in an Acidic Medium
}

\author{
Ibrahim Jimoh and Bishir Usman* \\ Department of Purke and Industrial Chemistry, Faculty of Physical Sciences, College of Natural \\ and Pharmaceutical Sciences, Bayero University Kano, P.M.B. 3011, Kano State, Nigeria \\ *Corresponding author: busman.chm@buk.edu.ng
}

Received July 26, 2018; accepted August 15, 2020

https://doi.org/10.4152/pea.202102105

\begin{abstract}
The corrosion inhibition effect of ethanol extract of Acacia nilotica leaves (ANLE) on mild steel in $0.1 \mathrm{M} \mathrm{H}_{2} \mathrm{SO}_{4}$, containing 0.1-0.5 g/L, has been studied using weight loss, Potentiodynamic Polarization (PDP), Fourier Transforms Infra-Red (FTIR) spectroscopy, UV-visible spectroscopy, High-Performance Liquid Chromatography (HPLC) and Scanning Electron Microscopy (SEM) methods. The results from weight loss and PDP show that the inhibition efficiency depends on the concentration of the plant extract, as well as on the time of exposure of the mild steel samples in $\mathrm{H}_{2} \mathrm{SO}_{4}$ solutions. The optimum inhibition efficiencies of the extract obtained from weight loss and potentiodynamic measurements were found to be $87.57 \%$ and $61.85 \%$, respectively. Thermodynamic parameters, such as $\mathrm{E}_{\mathrm{a}}, \Delta \mathrm{H}, \Delta \mathrm{G}$ and $\Delta \mathrm{S}$, were evaluated at $0.5 \mathrm{~g} / \mathrm{L}$, and the results were found to be $-78.54 \mathrm{~kJ} / \mathrm{mol}, 74.66 \mathrm{~kJ} / \mathrm{mol},-17.92 \mathrm{~kJ} / \mathrm{mol}$ and -90.59 $\mathrm{kJ} / \mathrm{mol}$, respectively. From the calculated values of activation energy and free energy of adsorption, and from the trend in the variation of inhibition efficiency with temperature, the inhibitor mechanism of adsorption was found to be physical adsorption, exothermic, spontaneous, being best described by Langmuir adsorption model, because the regression coefficients $\left(\mathrm{R}^{2}\right)$ values calculated from the plots were closest to unity, confirming a highest degree of linearity. Mild steel surface morphology, in ANLE presence and absence, was studied using SEM. FTIR spectroscopy and UV-visible spectroscopy analyses were used to confirm the adsorption process onto the metal surface. Spectra analysis obtained from FTIR study indicated that ANLE was adsorbed onto the mild steel surface via $\mathrm{C}-\mathrm{O}$ and $\mathrm{N}=\mathrm{O}$ functional groups. HPLC was also used to find the main component responsible for inhibition, at $5.990 \mathrm{~min}$, which was Catechin. The obtained results revealed that ANLE acts as a good inhibitor and could serve as an effective mild steel corrosion inhibitor in a $0.1 \mathrm{M} \mathrm{H}_{2} \mathrm{SO}_{4}$ solution.
\end{abstract}

Keywords: Acacia nilotica, corrosion, mild steel, tetraoxosulphate (VI) acid.

\section{Introduction}

Mild steel is one of the preferred materials often used in industries, due to its easy availability and good structural properties. Corrosion of metals such as iron and steel, due to exposure to aggressive environments, results in equipment mechanical failure, causes dangerous and costly damages to oil, gas and water 
pipelines, bridges, public buildings, vehicles, water and wastewater systems and even home appliances ${ }^{1,2}$. Therefore, corrosion protection processes for mild steel in aggressive acid and alkaline media are found to be important ${ }^{3}$.

Several kinds of research have been carried out on the inhibition of mild steel corrosion, due to its high technological value for a wide range of industrial applications. Generally, compounds containing heteroatoms such as N, O, P and $\mathrm{S}$ and a long carbon chain, as well as triple bonds or aromatic rings in their molecular structure, are used as inhibitors ${ }^{4,5}$. These compounds are expensive, toxic and non-eco-friendly.

Plant materials are inexpensive, non-toxic, readily available, eco-friendly and the richest source of heterocyclic compounds containing $\pi$ - electrons, and functional groups (such as $-\mathrm{C} \equiv \mathrm{C}-,-\mathrm{OR},-\mathrm{OH},-\mathrm{COOH},-\mathrm{NR}_{2},-\mathrm{NH}_{2}$, and -SR), which provide electrons that facilitate the inhibitor adsorption onto the metal surface. Recent developments in the area of corrosion assessment have been the studies of various plant extracts as corrosion inhibitors ${ }^{6-9}$. It has been established that the inhibitory actions of plant extracts are due to the presence of some organic compounds such as tannins, saponin, alkaloids, steroid, glycosides and amino $\operatorname{acids}^{10}$.

In view of this, the present study sought to investigate the inhibitory effect of ethanol extract of Acacia nilotica leaves on mild steel corrosion in an acidic medium, using weight loss, potentiodynamic polarization, FTIR sectroscopy, UV-visible spectroscopy, HPLC and SEM methods of monitoring corrosion.

\section{Materials and Methods \\ Material preparation}

The mild steel used for this study was obtained from the department of mechanical engineering, Bayero University, Kano-new campus. The mild steel sheets were of composition (wt\%): Mn (0.27), Al (0.04), C (0.066), Ca (0.01), Cr (0.041), Cu (0.023), Te (0.17), I (0.25), Cl (0.21), Sc (0.03), Sb (0.20), Eu (0.10), $\mathrm{Si}(0.13)$ and the remainder Fe (determined by ED-XRF). The sheets were mechanically pressed-cut into different coupons, each one with the dimensions 5 $\mathrm{x} 4 \mathrm{x} 0.11 \mathrm{~cm}$. Each coupon was degreased by washing with ethanol, rinsed with acetone and allowed to dry at the air, before being preserved in a desiccator. All reagents used for the study were analar grade, and double distilled water was used for their preparation.

\section{Coupon preparation}

The corrosion test was performed using coupons prepared from the mild steel which was cut into 100 samples of dimension $5 \times 4 \times 0.11 \mathrm{~cm}$. Emery paper of different grades $(240,400,800$ and 1000) was used for polishing the samples, which were washed in ethanol, degreased in acetone, dried in air, weighed and stored in desiccators, prior to corrosion studies. The initial weight of each sample was taken and recorded. 


\section{Plant extract preparation}

Samples of ANLE were air dried, ground, and soaked in a solution of ethanol for $48 \mathrm{~h}$, after which they were cooled and filtered. The filtrates were further subjected to evaporation at $352 \mathrm{~K}$, in order to leave the sample free of ethanol. Stock solutions of the obtained extract were used for preparing different concentrations by dissolving $0.1,0.2,0.3,0.4$, or $0.5 \mathrm{~g}$ of the extract in $1 \mathrm{~L}$ of 0.1 $\mathrm{M} \mathrm{H}_{2} \mathrm{SO}_{4}{ }^{10}$.

\section{Acid solution preparation}

A stock solution of $0.1 \mathrm{M} \mathrm{H}_{2} \mathrm{SO}_{4}$ was used as the corrodent for this study, and it was prepared from $98 \% \mathrm{H}_{2} \mathrm{SO}_{4}$ (Merck), by diluting $5.40 \mathrm{~mL}$ of concentrated $\mathrm{H}_{2} \mathrm{SO}_{4}$ Analar grade, in a $1000 \mathrm{~mL}$ volumetric flask containing $150 \mathrm{~mL}$ of distilled, which was used throughout the experiments for the preparation of solutions. The employed concentration range of ANLE ethanolic extract varied from 0.1 to $0.5 \mathrm{~g} / \mathrm{L}$.

\section{Experimental}

\section{Weight loss measurements}

Weight loss measurements were performed in a $250 \mathrm{~mL}$ beaker, at $303 \mathrm{~K}$. The solution volume used was $250 \mathrm{~mL}$, and the mild steel was weighed and immersed in the solution for $1 \mathrm{hr}$. After that, the mild steel sample was retrieved, washed with distilled water, rinsed with ethanol and acetone, dried and reweighed. From the initial and final weights of mild steel coupons, the weight loss $(\mathrm{g})$, corrosion rate $\left(\mathrm{g} / \mathrm{h} / \mathrm{cm}^{2}\right)$, inhibition efficiency $(\% \mathrm{I})$ and the degree of surface coverage $(\theta)$ were calculated using equations $1-3$, respectively.

$$
\begin{gathered}
\mathrm{CR}\left(\mathrm{g} / \mathrm{h} / \mathrm{cm}^{2}\right)=\frac{\Delta W}{A t} \\
\theta=1-\frac{W_{1}}{W_{2}} \\
\% \mathrm{I}=\left(1-\frac{W_{1}}{W_{2}}\right) \times 100
\end{gathered}
$$

where $W_{1}$ and $W_{2}$ are the weight losses (in $\mathrm{g} / \mathrm{dm}^{3}$ ) for mild steel coupons, in the inhibitor presence and absence, in $\mathrm{H}_{2} \mathrm{SO}_{4}$ solutions, respectively, $\theta$ is the degree of surface coverage of the inhibitor, $\mathrm{A}$ is the area of the metal coupon (in $\mathrm{cm}^{2}$ ), $\mathrm{t}$ is the period of immersion (in hrs.) and $\Delta \mathrm{W}$ is the weight loss of the mild steel coupon (in gram) after time, $t$.

\section{Potentiodynamic polarization}

The potentiodynamic polarization measurements were carried out using three electrodes, namely, working electrode (mild steel), reference electrode (saturated $\mathrm{Ag} / \mathrm{AgCl}$ ) and counter electrode (graphite rod). Polarization measurements were carried out using Autolab PGSTAT 302N, which was connected to an acquisition 
system to control the experiments, and NOVA software packaged version 1.10.1.9 was used for analysing the data.

Before the polarization, the mild steel sample was prepared with the dimensions of $5 \times 4 \times 0.11 \mathrm{~cm}$. The sample was ground and polished with an emery paper of grade 240, 400, 800 and 1000, respectively, washed with distilled water, followed by acetone, dried with air, and kept in desiccators, prior to the experiment. The used polarization parameters are a scan rate of $5 \mathrm{mVs}^{-1}$, with the potentiostat range of $\pm 250 \mathrm{mV}$, at open potential current (OPC), with a steady time of $15 \mathrm{~min}$. From the Tafel analysis, corrosion current density ( $\mathrm{I}_{\text {corr }}$ ), equilibrium corrosion potential ( $\left.\mathrm{E}_{\text {corr }}\right)$, corrosion rate $(\mathrm{CR})$ and linear polarization resistance $\left(R_{p}\right)$ values were obtained in a static solution by the software. The inhibition efficiency $\left(\mu_{\mathrm{p}}\right)$, at different inhibitor concentrations, was calculated by the equations (4) and (5):

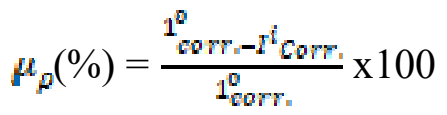

where $\mathrm{I}^{0}$ corr and $\mathrm{I}^{\mathrm{i}}$ corr belong to corrosion current density, in the extract absence and presence.

Inhibition efficiency from polarization resistance values ( $\left.\mu_{\mathrm{PR}}\right)$ was determined by the following formula:

$$
\mu_{P R}(\%)=\frac{R_{P-R}^{i}}{R_{P}^{i}} \times 100
$$

where $R_{P}^{i}$ and $R_{F}^{0}$ denote linear polarization resistance, in the inhibitors presence and absence.

\section{Fourier Transform Infrared Spectrophotometry (FTIR)}

FTIR analyses of the inhibitor and that of the corrosion products (in the presence and absence of the respective inhibitors), were carried out using an FTIR instrument, 630 Cary series Agilent technologies. Two coupons were separately dipped in $250 \mathrm{~mL}$ of $0.5 \mathrm{~g} / \mathrm{L}$ inhibitor concentration, for 2 days, to form an adsorbed layer, after which they were retrieved, dried and scraped with a sharp blade. The scrapped were collected for analysis. The samples were prepared using $\mathrm{KBr}$, and the analysis was done by scanning the sample through a wave number range from 400 to $4000 \mathrm{~cm}^{-1}$.

\section{UV-visible spectroscopy}

The characterization of the extract was carried out by Perkin Elmer UV WinLab Data Processor and Viewer Version 1.0 UV/Visible spectrometer. Then, $0.5 \mathrm{~g} / \mathrm{L}$ of the prepared solution were inspected within $200-900 \mathrm{~nm}$ wavelength range. The coupons $(5 \times 4 \times 0.11 \mathrm{~cm})$ were separately immersed in the solutions containing $0.1 \mathrm{M} \mathrm{H}_{2} \mathrm{SO}_{4}$, with an effective concentration of leaves extracts, to examine the stability of the inhibitor molecules on their surface. After $2 \mathrm{hrs}$, the 
test samples were removed, cleaned with distilled water, dip-washed thrice and then immersed for $30 \mathrm{~min}$ in distilled water, followed by smooth rubbing of the mild steel surface. These solutions were again examined and compared with the spectrum of pure extracts.

\section{High Performance Liquid Chromatography (HPLC)}

Samples of Acacia nilotica leaves were dried, ground, and soaked in a solution of ethanol for $48 \mathrm{~h}$, after which they were cooled and filtered. The filtrates were further subjected to evaporation at $352 \mathrm{~K}$, in order to leave the sample free of the ethanol. The concentrate was then dissolved in $10 \mathrm{~mL}$ of HPLC-grade methanol. The chromatography of the extract was performed by HPLC (Shimadzu LC solution, UV detector). The software package used for analyzing results was Shimadzu LC solution HPLC control and Auto-sampling. Chromatographic analysis was carried out using a column, C- 18 , at $38^{\circ} \mathrm{C}$. Before the analysis, the column was equilibrated with the following elements: mobile phase; Acetonitrile: water (binary mode), in the ratio of $80: 20$; flow rate of $0.15 \mathrm{~mL} / \mathrm{min}$; running time of $20 \mathrm{~min}$; and detection at $254 \mathrm{~nm} .30 \mu \mathrm{L}$ of the extract were filtered by a PTFE syringe $(0.45 \mathrm{~mm})$, Whatman (U.K.). $10 \mu \mathrm{L}$ of the extract was injected through a syringe in an HPLC instrument for analysis. The compounds in the extract were identified by comparison of their experimental retention times with standard retention time of pure compounds. In this research, attention was only focused on the identification of the main chemical constituent of ethanol extracts of ANLE.

\section{Surface analysis}

Surface morphology of the mild steel coupons, before and after inhibition, was studied using an Inspect S50 Scanning Electron Microscope. 5 x 4 x $0.11 \mathrm{~cm}$ coupons were dipped in a blank solution, and in $0.5 \mathrm{~g} / \mathrm{L}$ of the inhibitor solution, for 2 days. The coupons were then retrieved, rinsed with distilled water and dried at the air. Each sample was mounted on a metal stub and sputtered with gold, in order to make the sample conductive. Scanned images were taken at an accelerating voltage of 2.00 and $12.50 \mathrm{kV}^{11}$.

\section{Results and discussion \\ Weight loss measurement \\ Effect of inhibitor concentration}

The effect of ANLE extract concentration in relation to corrosion rate and inhibition efficiency, at $303 \mathrm{~K}$, for mild steel corrosion, in $0.1 \mathrm{M} \mathrm{H}_{2} \mathrm{SO}_{4}$, in the absence and presence of various concentrations of the plant leaves extract, is shown in Figs. 1 and 2, respectively. From the plot (Fig. 1), it can be observed that the corrosion rate of mild steel coupons in $0.1 \mathrm{M} \mathrm{H}_{2} \mathrm{SO}_{4}$ decreased with higher concentrations of the plant extract. 


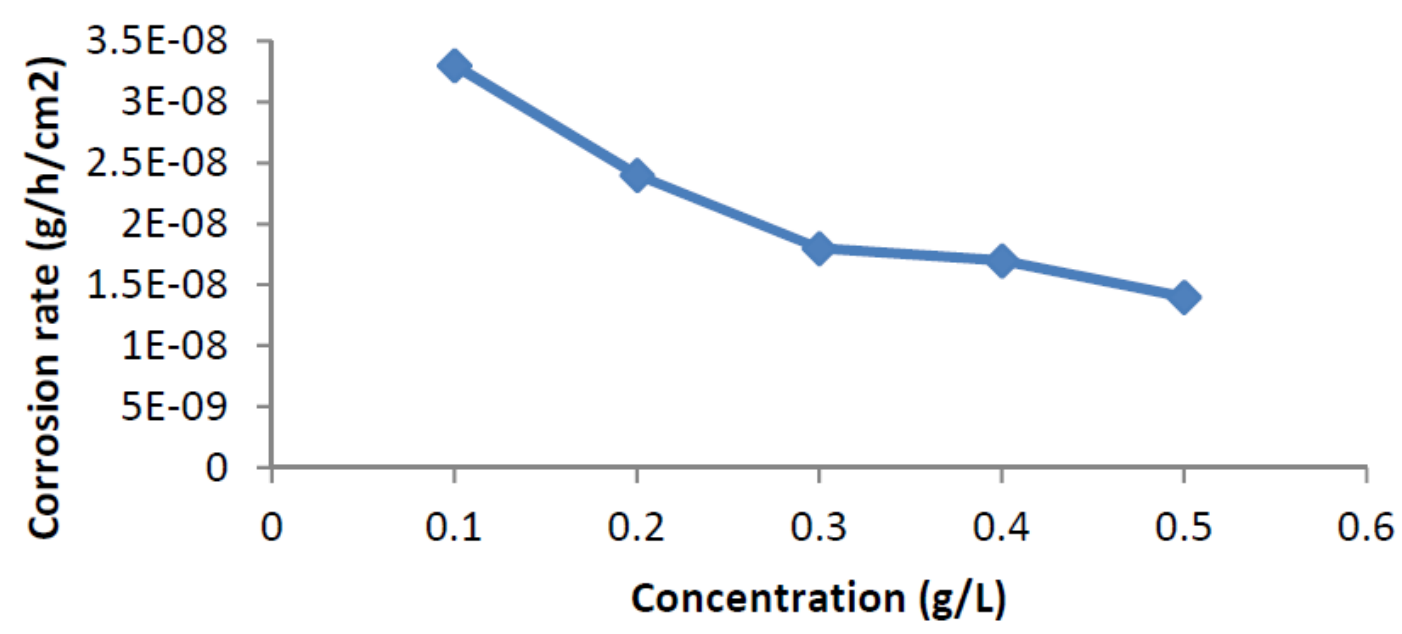

Figure 1. Variation of mild steel corrosion rate $\left(\mathrm{g} / \mathrm{h} / \mathrm{cm}^{2}\right)$, as a function of various concentrations of Acacia nilotica leaves extract in $0.1 \mathrm{M} \mathrm{H}_{2} \mathrm{SO}_{4}$, at $303 \mathrm{~K}$.

This is due to the fact that, as the concentration of the plant extract increased, there was an increase in the surface coverage of the adsorbed extract onto the mild steel surface, which provided an impediment and, consequently, retarded metal dissolution ${ }^{12}$. This is in agreement with findings of Niamien et al. ${ }^{13}$; Olasehinde et al. ${ }^{14}$. Furthermore, the inhibition efficiency (Fig. 2) of the extract was observed to increase with a rise in the inhibitor concentrations. This may be due to an increment in the surface coverage, which caused retardation of metal corrosion ${ }^{12}$.

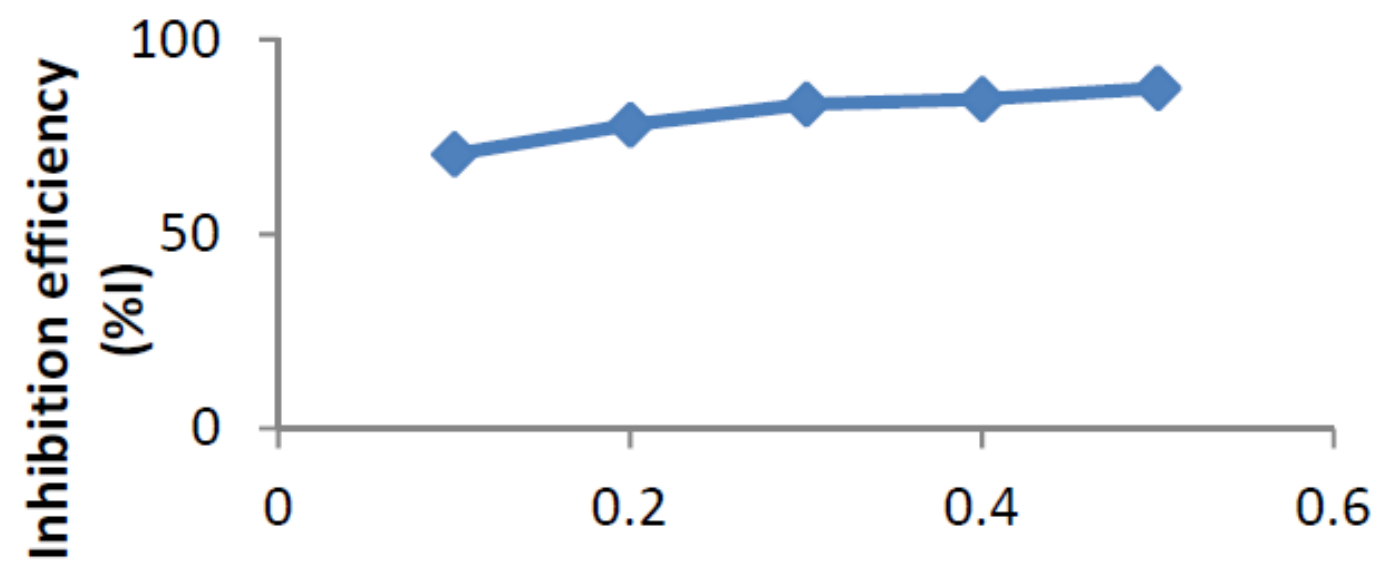

\section{Concentration(g/L)}

Figure 2. Variation of Inhibition Efficiency (\%IE) against various concentrations of ANLE extract, for mild steel corrosion, in $0.1 \mathrm{M} \mathrm{H}_{2} \mathrm{SO}_{4}$, at $303 \mathrm{~K}$.

\section{Effect of immersion time}

Fig. 3 shows the weight loss-time curve for mild steel corrosion, without and with varying concentrations of ANLE extract in $0.1 \mathrm{M} \mathrm{H}_{2} \mathrm{SO}_{4}$, at $303 \mathrm{~K}$. From the 
figure, it is evident that the weight loss of mild steel increases with an increase in the period of contact, but decreases in the inhibitor presence.

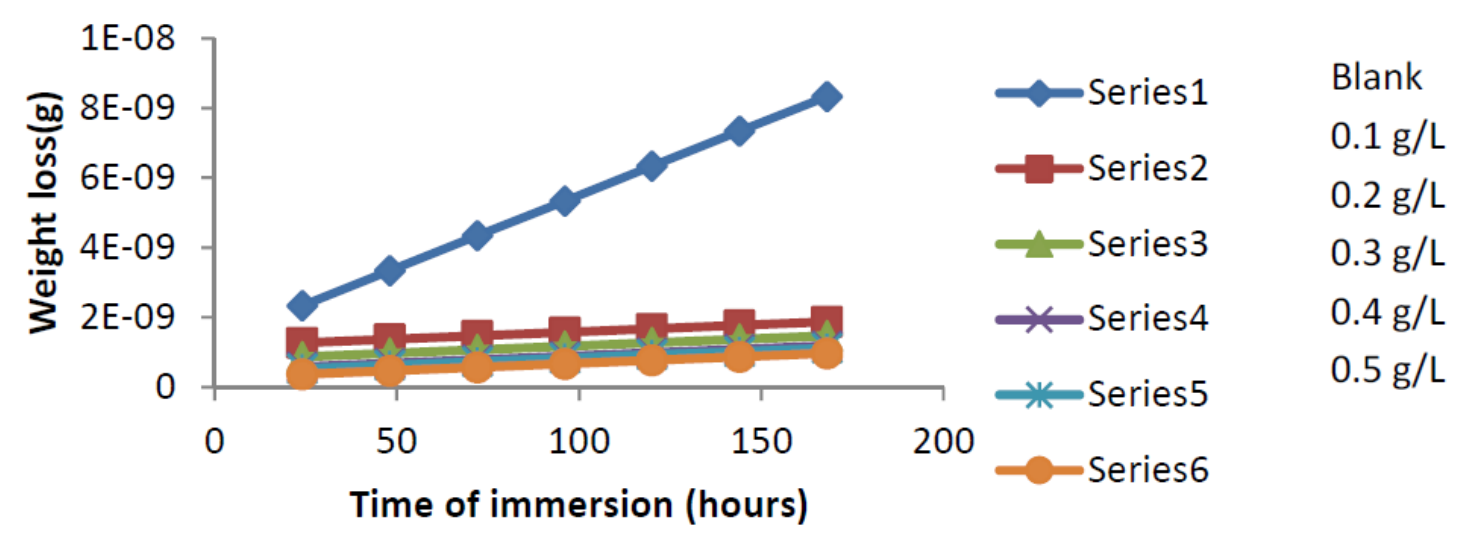

Figure 3. Effect of immersion time (hours) on mild steel corrosion rate in $0.1 \mathrm{M} \mathrm{H}_{2} \mathrm{SO}_{4}$, in the absence and presence of ANLE extract, at $303 \mathrm{~K}$.

It is also clear that weight loss reduces with a rise in the inhibitor concentration, implying that ethanol extract of A. nilotica is an adsorption inhibitor for mild steel corrosion in $\mathrm{H}_{2} \mathrm{SO}_{4}$, and that mild steel corrosion rates and inhibition efficiency increase with a rise in the period of contact ${ }^{15,16}$.

\section{Effect of temperature}

The variation in mild steel corrosion rate in $0.1 \mathrm{M} \mathrm{H}_{2} \mathrm{SO}_{4}$, in the presence and absence of ANLE extract inhibitor, at different temperatures, has been studied, and it was evident from Table 1 and the plot in Fig. 4 that mild steel corrosion rate, with or without extract, increased with a rise in temperature ${ }^{4}$.

Table 1. Inhibition efficiencies (\%IE) and corrosion rates for mild steel corrosion, in the absence and presence of various concentrations of the extract in $0.1 \mathrm{M} \mathrm{H}_{2} \mathrm{SO}_{4}$, at 303 $333 \mathrm{~K}$.

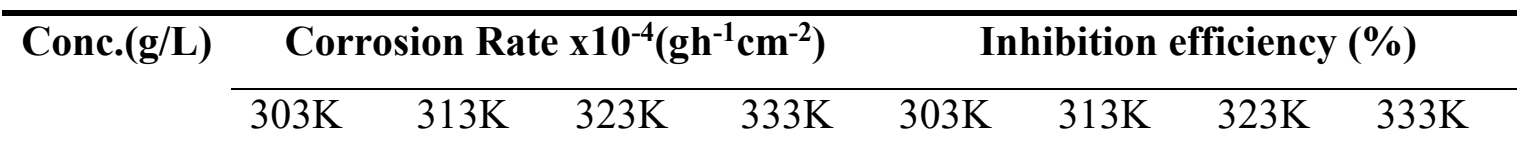

\begin{tabular}{lllllllll}
\hline Blank & 1.11 & 3.45 & 5.79 & 7.93 & - & - & - & - \\
0.1 & 0.33 & 1.19 & 2.30 & 3.86 & 70.54 & 65.45 & 60.23 & 51.34 \\
0.2 & 0.24 & 0.93 & 2.05 & 3.42 & 78.04 & 72.95 & 64.61 & 56.90 \\
0.3 & 0.18 & 0.75 & 1.53 & 2.88 & 83.40 & 78.31 & 73.59 & 63.73 \\
0.4 & 0.17 & 0.58 & 1.39 & 2.54 & 84.68 & 83.27 & 76.07 & 67.99 \\
0.5 & 0.14 & 0.52 & 1.10 & 2.32 & 87.57 & 84.92 & 80.98 & 70.69 \\
\hline
\end{tabular}




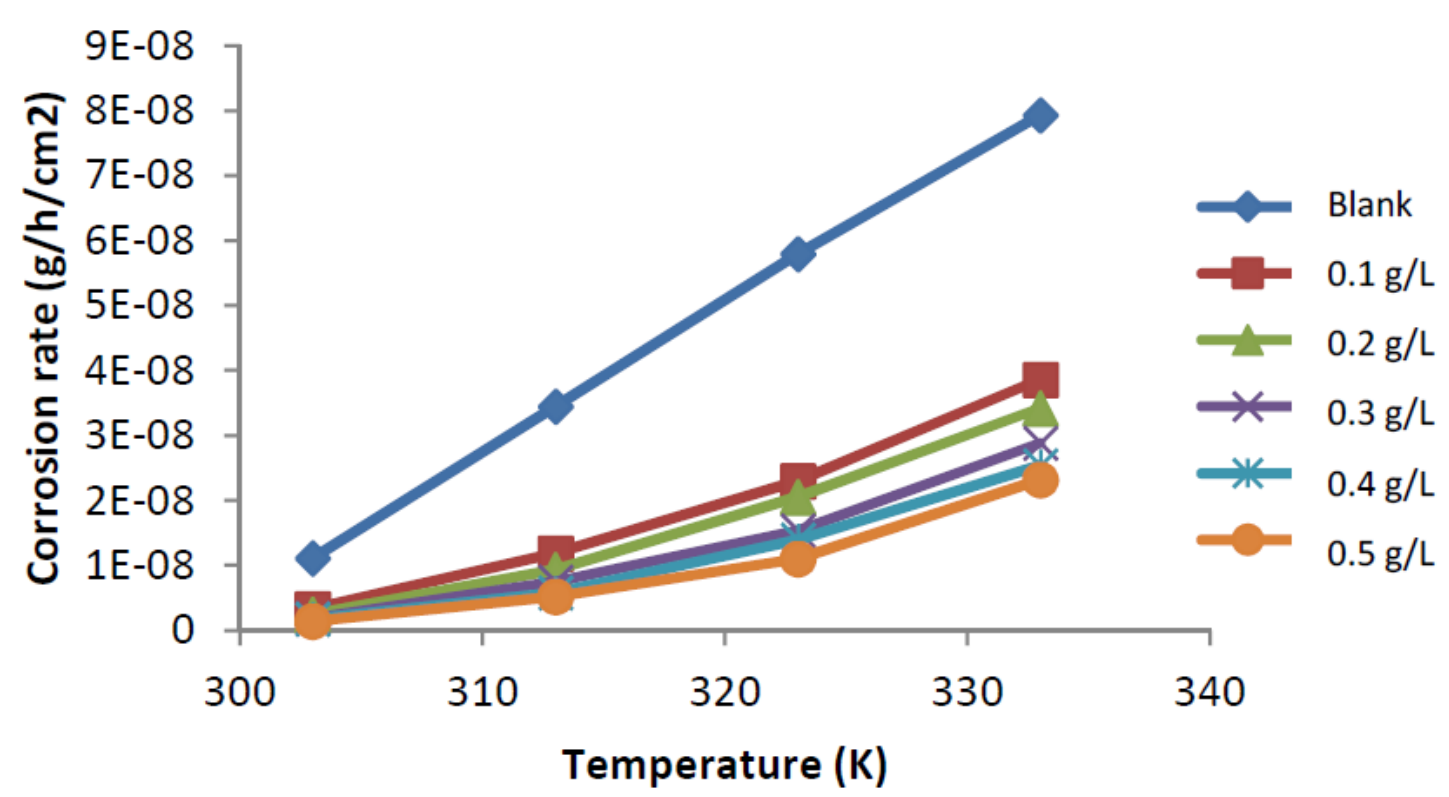

Figure 4. Variation of mild steel corrosion rate against temperature $(303-333 \mathrm{~K})$, in the absence and presence of different concentrations of ANLE extract in $0.1 \mathrm{M} \mathrm{H}_{2} \mathrm{SO}_{4}$.

This is due to the fact that, as the temperature increased from 303 to $333 \mathrm{~K}$, mild steel coupons corrosion rate also increased, as a result of an increase in average kinetic energy of the reacting molecules ${ }^{17}$. However, the corrosion rate is retarded in the plant extract presence. The corrosion rate increases more rapidly with temperature in the extract absence. Two observations could be drawn from the results: (i). The mild steel surface is effectively damaged in the acidic medium ${ }^{18}$ and (ii) ANLE extract is a strong inhibitor for mild steel corrosion in $0.1 \mathrm{M} \mathrm{H}_{2} \mathrm{SO}_{4}$, at a lower temperature.

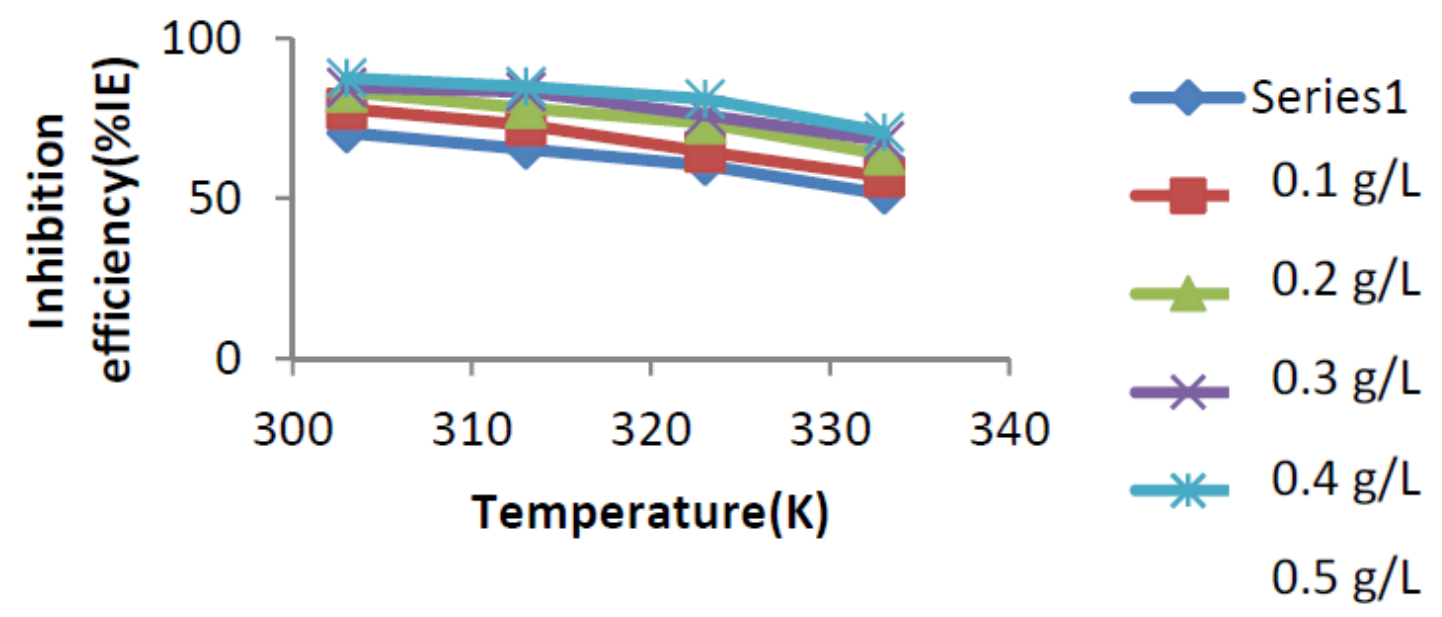

Figure 5. Variation of Inhibition Efficiency (\%IE) against temperature for mild steel corrosion in $0.1 \mathrm{M} \mathrm{H}_{2} \mathrm{SO}_{4}$, in the presence and absence of Acaci nilotica leaves extract. 
Furthermore, it is observed in Fig. 5 and Table 1 that the inhibition efficiency of the plant extract decreased with a rise in temperature for all the inhibitor concentrations. This may be as a result of the increasing solubility of the adsorbed protective inhibitor barrier on the mild steel surface, thereby increasing the susceptibility of these coupons to dissolution in the acidic media ${ }^{14}$.

\section{Stability of inhibitor}

The stability of ethanol extract of $A$. nilotica for mild steel corrosion in $\mathrm{H}_{2} \mathrm{SO}_{4}$ (over a time range) was also studied by plotting values of inhibition efficiency versus the period of contact, as shown in Fig. 6. The plots indicate that, at $303 \mathrm{~K}$, the ethanol extract of $A$. nilotica retained more than $87 \%$ of its inhibition efficiency, even after 168 hours of immersion ${ }^{10}$.

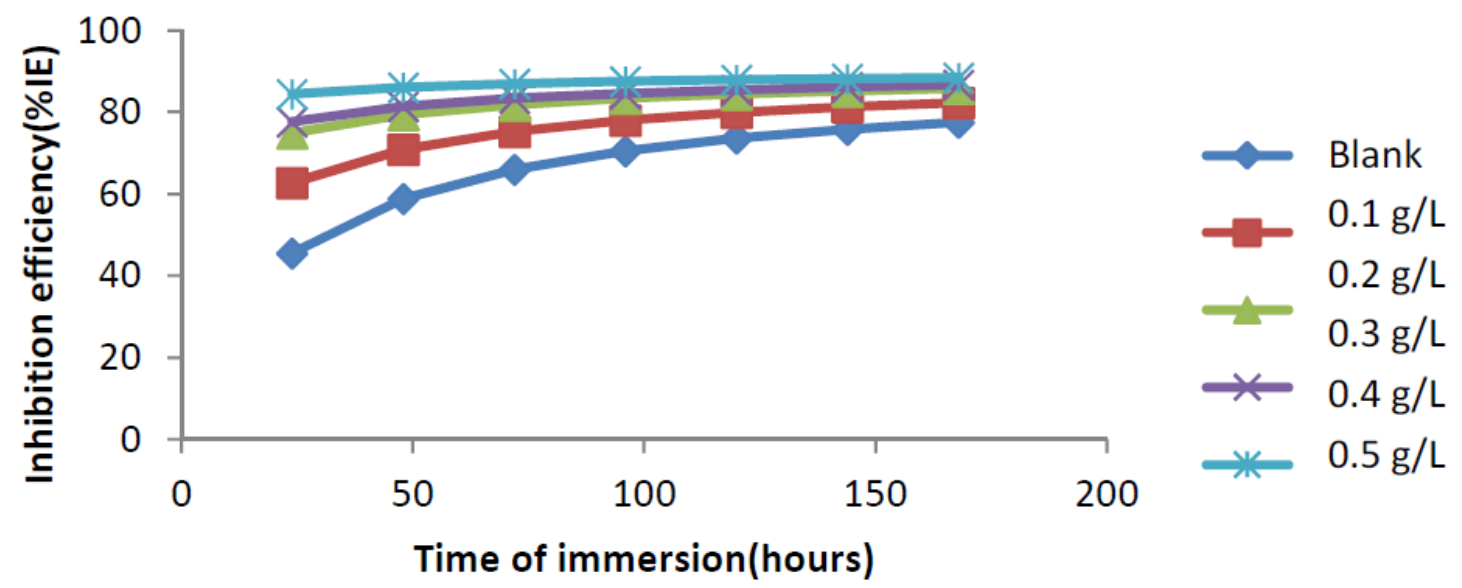

Figure 6. Effect of immersion time (hours) on inhibition efficiency (\%IE) of ANLE extract on mild steel dissolution in $0.1 \mathrm{M} \mathrm{H}_{2} \mathrm{SO}_{4}$, at $303 \mathrm{~K}$.

\section{Kinetic study}

The kinetics of mild steel corrosion in a $0.1 \mathrm{M} \mathrm{H}_{2} \mathrm{SO}_{4}$ solution was studied by fitting data obtained from weight loss measurements into different kinetic equations. The plots of -log (weight loss) against time (hours,) at $303 \mathrm{~K}$ and other studied temperatures studied, were found to be linear, which confirms a firstorder reaction kinetics, with respect to mild steel corrosion in $0.1 \mathrm{M} \mathrm{H}_{2} \mathrm{SO}_{4}$ solutions, in the extract presence (Fig. 7). The rate constant and half- life time were derived as follow ${ }^{10}$ : 


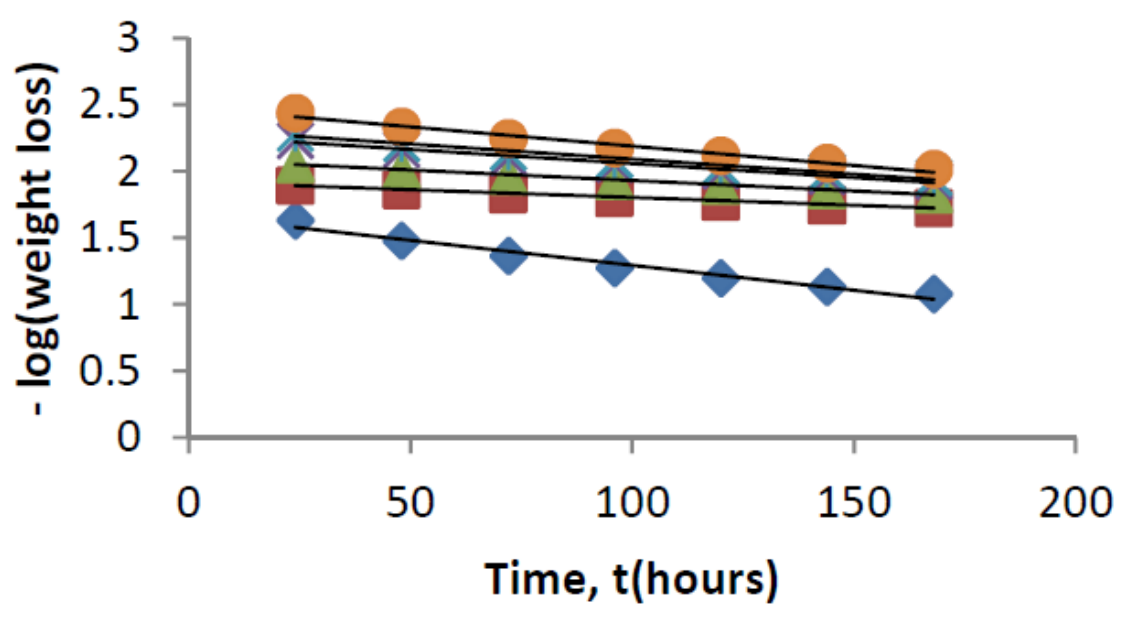

Blank

$0.1 \mathrm{~g} / \mathrm{L}$

$\Delta .2 \mathrm{~g} / \mathrm{L}$

$\times 0.3 \mathrm{~g} / \mathrm{L}$

* $0.4 \mathrm{~g} / \mathrm{L}$

$0.5 \mathrm{~g} / \mathrm{L}$

Figure 7. Variation of - $\log$ weight $\operatorname{loss}(\mathrm{g})$ against time(hours) for mild steel coupons in a $0.1 \mathrm{M} \mathrm{H}_{2} \mathrm{SO}_{4}$ solution containing ANLE extract, at $303 \mathrm{~K}$.

\section{Determination of rate constant}

If the initial concentration of $\mathrm{Fe}$ in mild steel is $\mathrm{a}_{0}$, and the final concentration of the corrosion product formed after time, $\mathrm{t}$, is $\mathrm{x}$ mole, then the kinetic equation of the reaction can be represented as equation 6 :

$$
\frac{d_{x}}{d_{t}}=K_{1}\left(a_{0}-\mathrm{X}\right)
$$

where $K_{1}$ is the first order reaction rate constant. Upon rearrangement, equation 6 yields equation 7 and upon integration, equation 8 and equation 9 are obtained.

$$
\begin{gathered}
\frac{d x}{\left(a_{0}-x\right)}=K_{1} d_{t} \\
-\ln \left(\mathrm{a}_{0}-\mathrm{x}\right)=K_{1} t \\
-\log (\text { weight loss })=\frac{K_{1} t}{2,303}
\end{gathered}
$$

where $K_{1}$ is the first order reaction rate constant and $t$ is the time in hours. From the slopes of the plots (at various inhibitor concentrations), obtained $K_{1}$ values are presented in Table $2^{16,19,20}$.

\section{Determination of half life}

For a first-order reaction, the half-life is related to the rate constant, as follows ${ }^{10}$ :

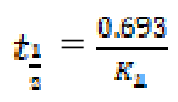

Values of kinetic parameters deduced from the plots are presented in Table 2. From the obtained results, it is evident that the half-lives of mild steel, in 
solutions of $\mathrm{H}_{2} \mathrm{SO}_{4}$ containing various inhibitors concentrations, are greater than the half-life of mild steel in the blank solution (i.e. $0.1 \mathrm{M} \mathrm{H}_{2} \mathrm{SO}_{4}$, without any inhibitor).

Table 2. Kinetic parameters for the corrosion of mild steel in $0.1 \mathrm{M} \mathrm{H}_{2} \mathrm{SO}_{4}$ containing various concentration of ANLE ethanol extract.

\begin{tabular}{clrc}
\hline $\begin{array}{c}\text { Inhibitor concentration } \\
(\mathbf{g} / \mathbf{L})\end{array}$ & $\begin{array}{c}\text { Rate constant } \\
\mathbf{k}_{\mathbf{1}}\left(\mathbf{h} \mathbf{r}^{-\mathbf{1}}\right) \mathbf{x} \mathbf{1 0}^{-\mathbf{4}}\end{array}$ & $\begin{array}{r}\text { Half-life } \\
\mathbf{t}_{\mathbf{1} / \mathbf{2}}(\mathbf{h r s}) .\end{array}$ & $\mathbf{R}^{\mathbf{2}}$ \\
& & & \\
\hline Blank & 85.222 & 81.33 & 0.9672 \\
0.1 & 66.787 & 103.76 & 0.9812 \\
0.2 & 52.969 & 130.83 & 0.9857 \\
0.3 & 48.363 & 143.29 & 0.9900 \\
0.4 & 36.848 & 188.07 & 0.9943 \\
0.5 & 27.636 & 250.76 & 0.9967 \\
\hline
\end{tabular}

The increase in half-life $\left(\mathrm{t}_{1 / 2}\right)$, shown when the extract is present, further supports mild steel corrosion inhibition in $0.1 \mathrm{M} \mathrm{H}_{2} \mathrm{SO}_{4}$. The increase in half-life indicates more protection coverage of the metals by the extract. Therefore, ANLE ethanol extract increases the half-life of mild steel in $\mathrm{H}_{2} \mathrm{SO}_{4}$ solutions ${ }^{21}$.

\section{Thermodynamic and adsorption study}

The activation energy $\left(E_{a}\right)$ can be calculated from the Arrhenius equation (equation 11). Its logarithmic form, $\mathrm{T}_{1}(303 \mathrm{~K})$ and $\mathrm{T}_{2}(333 \mathrm{~K})$, it is known, (i.e. $\mathrm{CR}_{1}$ and $\mathrm{CR}_{2}$, respectively), then, equation 12 can be transformed into equation 13:

$$
\begin{gathered}
\mathrm{CR}=\mathrm{A} \exp \left(\frac{-E a}{\pi T}\right) \\
\log \mathrm{CR}=\log \mathrm{A}-\frac{E a}{2.303 R T} \\
\log \frac{C R_{2}}{C R_{1}}=\frac{E a}{2,303}\left(\frac{1}{T_{1}}-\frac{1}{T_{1}}\right)
\end{gathered}
$$

where $\mathrm{CR}$ is the metal corrosion rate, $\mathrm{A}$ is the Arrhenius constant $E_{a}$ is the activation energy, $\mathrm{R}$ is the universal gas constant and $\mathrm{T}$ is the absolute temperature of the system, in Kelvin (K).

\section{Heat of adsorption determination}

The heat of adsorption of the inhibitors was calculated from the trend of surface coverage with temperature, using equation $14^{10,22}$ : 


$$
\mathrm{Q}_{\text {ads }}=2.303 \mathrm{R}\left[\log \left(\frac{\theta_{2}}{1-\theta_{2}}\right)-\log \left(\frac{\theta_{1}}{1-\theta_{1}}\right)\right]
$$

where $\theta_{1}$ and $\theta_{2}$ are values of the degree of surface coverage at temperatures $T_{1}$ and $T_{2}$, respectively, and $R$ is the gas constant.

Table 3 shows $E_{a}$ and $Q_{\text {ads }}$ calculated values, from which the values for the apparent activation energy for the corrosion process, in the extract presence, are higher than those in the blank (i.e $0.1 \mathrm{M} \mathrm{H}_{2} \mathrm{SO}_{4}$ solution). The increase in activation energy, in the presence of the extract, implies physisorption, with the formation of an adsorptive film of an electrostatic character.

Table 3. Heat of adsorption and thermodynamic parameters for mild steel dissolution in $0.1 \mathrm{M} \mathrm{H}_{2} \mathrm{SO}_{4}$, in the absence and presence of various concentration of ANLE ethanol extract, at $303-333 \mathrm{~K}$.

\begin{tabular}{|c|c|c|c|c|}
\hline $\begin{array}{c}\text { Inhibitor } \\
\text { concentratio } \\
\text { n } \\
(\mathrm{g} / \mathrm{L})\end{array}$ & $\begin{array}{c}\text { Ea } \\
\left(\mathrm{kJmol}^{-}\right. \\
\text {1) }\end{array}$ & $\begin{array}{c}\text {-Qads } \\
\text { (kJmol- } \\
\text { 1) }\end{array}$ & $\begin{array}{c}-\Delta H_{\mathrm{ads}} \\
\left(\mathrm{kJmol}^{-1}\right)\end{array}$ & $\begin{array}{c}-\Delta S a d s \\
\left(\mathrm{kJmol}^{-}\right. \\
1)\end{array}$ \\
\hline Blank & 54.99 & - & 51.63 & 148.82 \\
\hline 0.1 & 68.78 & 23.92 & 65.22 & 114.19 \\
\hline 0.2 & 74.30 & 27.51 & 71.29 & 96.76 \\
\hline 0.3 & 75.63 & 27.43 & 72.99 & 94.51 \\
\hline 0.4 & 77.54 & 28.25 & 73.58 & 91.56 \\
\hline 0.5 & 78.52 & 30.68 & 74.66 & 90.59 \\
\hline
\end{tabular}

This shows that the adsorbed plant extract provided a physical barrier to the mass transfer, causing a decrease in the corrosion rate. This conforms to the findings of Oguzie et al. ${ }^{9}$, Adeyemi and Olubomehin ${ }^{23}$ and Olasehinde et al. ${ }^{14}$. Studies have also shown that $E_{a}$ values of $80 \mathrm{~kJ} \mathrm{~mol}^{-1}$ show physisorption ${ }^{2,14,24}$. From Table 3, it can be observed that $\mathrm{E}_{\mathrm{a}}$ values were lower than $80 \mathrm{~kJ} \mathrm{~mol}^{-1}$, confirming a physisorption, which is characterized by a reduction in inhibition efficiency, with a rise in temperature. $Q_{\text {ads }}$ negative values presented on Table 3 imply that the extract adsorption onto the metal surface is an exothermic process $22,25,26$.

\section{Enthalpy and entropy determination}

Thermodynamic parameters, such as enthalpy $(\Delta \mathrm{H})$ and entropy $(\Delta \mathrm{S})$ of the corrosion process activation may be evaluated by the temperature effect. The enthalpy and entropy of the corrosion process activation were calculated from the transition state equation ${ }^{27,28}$ : 


$$
\log \left(\frac{C R}{T}\right)=\left[\log \left(\frac{R}{W h}\right)+\frac{\Delta S}{2,303 R}\right]-\frac{\Delta H}{2,303 \pi T}
$$

where $\mathrm{CR}$ is the corrosion rate, $\mathrm{T}$ is the absolute temperature, $\mathrm{R}$ is the molar gas constant $\left(8.314 \mathrm{~J} \mathrm{~mol}^{-1} \mathrm{~K}\right), \mathrm{N}$ is Avogadro's constant $\left(6.0225 \times 10^{23} \mathrm{~mol}^{-1}\right)$ and $h$ is the Planck's constant $\left(6.6261 \times 10^{-34} \mathrm{JS}\right)$. A plot of $\log (\mathrm{CR} / \mathrm{T})$ against $1 / \mathrm{T}$ is a straight-line graph (see Fig. 8), with a slope of $\Delta H / 2.303 R$ Tand an intercept of $[\log (\mathrm{R} / \mathrm{Nh})+\Delta \mathrm{S} / 2.303 \mathrm{R}]$.

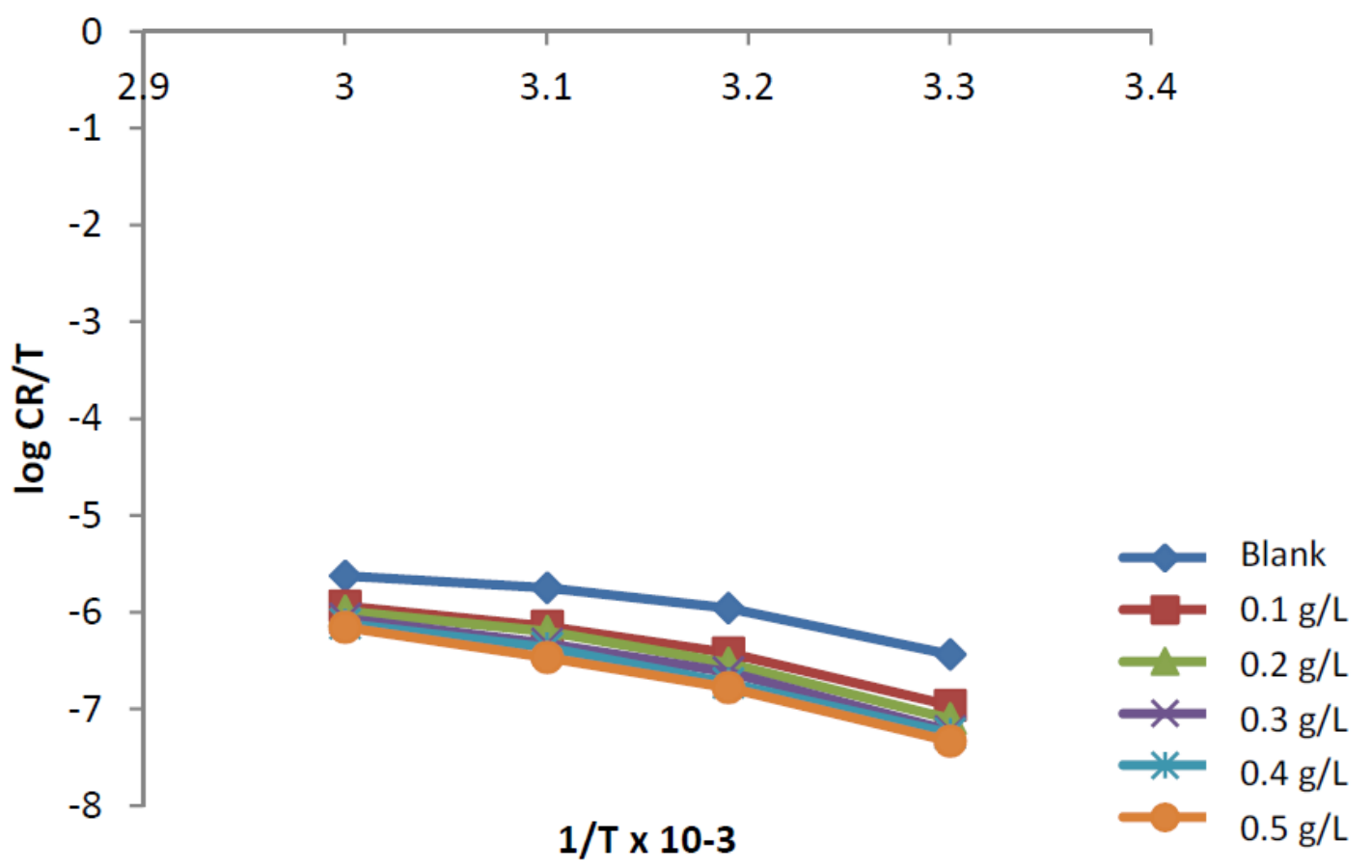

Figure 8. Transition state plots for mild steel corrosion, in the absence and presence of different concentrations of ANLE extract.

From the slope and the intercept, $\Delta \mathrm{H}$ and $\Delta \mathrm{S}$ were calculated as reported by Abiola et al. ${ }^{1}$. The results presented in Table 3 show that the enthalpies of activation values were all negative for ANLE ethanol extract, which shows the exothermic nature of the mild steel dissolution process. Also, the entropies of activation were negative, implying that the activation complex represents association steps, and that the reaction was spontaneous and feasible. These results were in agreement with the previous study ${ }^{26}$.

\section{Adsorption isotherms}

Adsorption isotherms give information about the interaction among adsorbed molecules, as well as their interactions with the metal surface. The adsorption characteristics of the extract were evaluated by fitting data obtained for the degree of surface coverage, from weight loss experiment, at 303 - 333K, into various adsorption isotherms, and it were found to best fit the Langmuir models (Fig.9). The functional and linear forms of these isotherm models are given in Table $4^{7,8}$. 


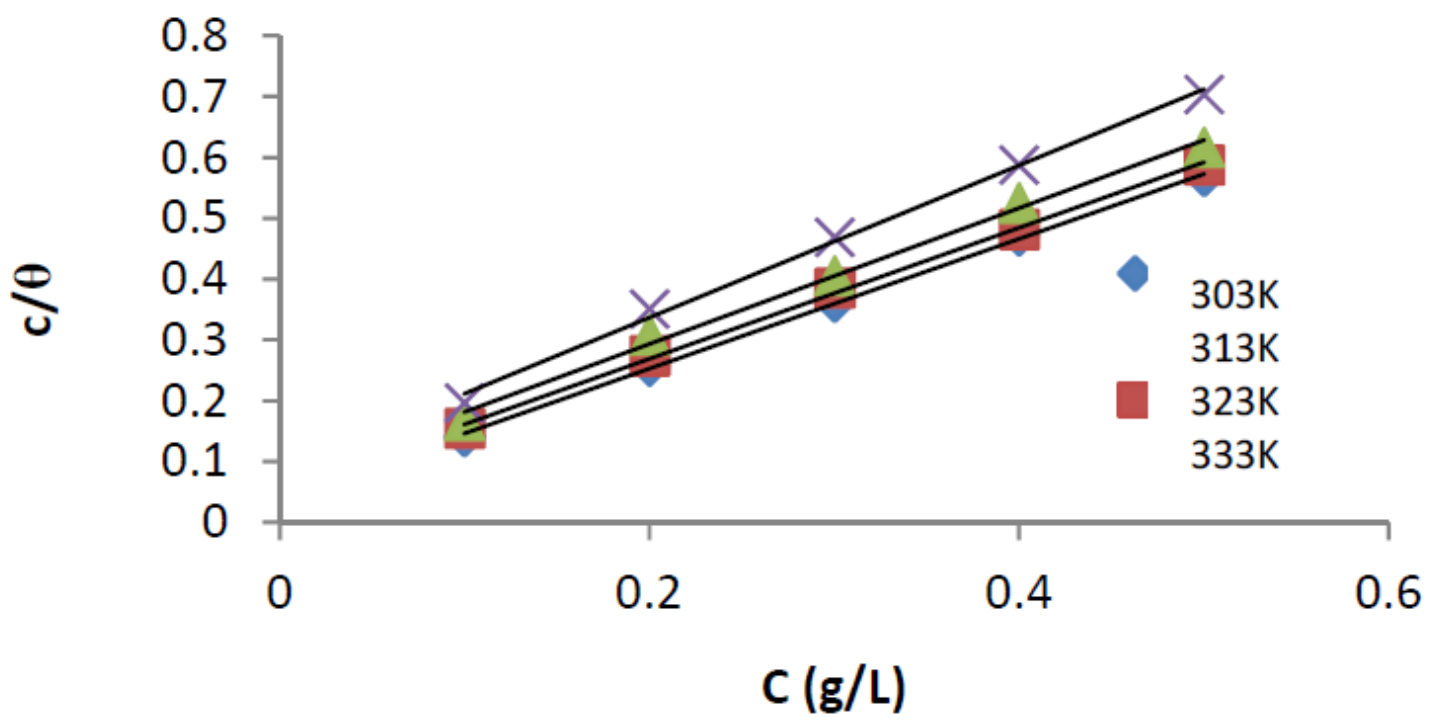

Figure 9. Langmuir isotherm for the adsorption of ANLE extract on the mild steel surface, in $0.1 \mathrm{M} \mathrm{H}_{2} \mathrm{SO}_{4}$, at $303-333 \mathrm{~K}$.

Table 4. Functional and linear forms of tested adsorption isotherm models.

\begin{tabular}{lll}
\hline Isotherm & Functional form & Linear form \\
\hline Langmuir & $\mathrm{K}_{\mathrm{ads}} \mathrm{C}=\frac{\theta}{1-\theta}$ & $\frac{c}{\theta}=\frac{1}{\kappa_{\text {rds }}}+\mathrm{C}$ \\
& $\mathrm{K}_{\mathrm{ads}} \mathrm{C}=\exp (\mathrm{f} \theta)$ & $-2 \alpha=2.303\left(\log \mathrm{K}_{\mathrm{ads}}+\log \mathrm{C}\right)$ \\
Temkin & With $\mathrm{f}=2 \alpha$ & \\
Freundlich & $\mathrm{K}_{\mathrm{ads}} \mathrm{C}^{\mathrm{n}}=0$ & $\log \theta=\log \mathrm{K}_{\mathrm{ads}}-\mathrm{n} \log \mathrm{C}$ \\
& with $0<\mathrm{n}<1$ & \\
\hline
\end{tabular}

where $\theta$ is the degree of the inhibitor surface coverage, $\mathrm{C}$ is the inhibitor concentration, $\propto$ is the molecular interaction parameter and $\mathrm{K}_{\mathrm{ads}}$ is the adsorption equilibrium constant. 
Table 5. Parameters of various adsorption isotherms for the adsorption of ANLE extract on a mild steel surface, at 303-333 K.

\begin{tabular}{lccccc}
\hline Isotherm & Intercept & Slope & $\mathbf{K}_{\text {ads }}$ & $\mathbf{R}^{\mathbf{2}}$ & $-\Delta \mathbf{G}^{\mathbf{0}} \mathbf{a d s}$ \\
\hline Langmuir & & & & & \\
$303 \mathrm{~K}$ & 0.039 & 1.069 & 25.641 & 0.999 & 18.294 \\
$313 \mathrm{~K}$ & 0.054 & 1.076 & 18.519 & 0.999 & 18.051 \\
$323 \mathrm{~K}$ & 0.069 & 1.118 & 14.493 & 0.995 & 17.969 \\
$333 \mathrm{~K}$ & 0.086 & 1.253 & 11.628 & 0.996 & 17.915 \\
\hline Temkin & & & & & \\
$303 \mathrm{~K}$ & 0.951 & 0.241 & 1.052 & 0.997 & 10.247 \\
$313 \mathrm{~K}$ & 0.939 & 0.292 & 1.065 & 0.995 & 10.618 \\
$323 \mathrm{~K}$ & 0.889 & 0.302 & 1.125 & 0.997 & 11.104 \\
$333 \mathrm{~K}$ & 0.793 & 0.293 & 1.261 & 0.982 & 11.764 \\
\hline Freundlich & & & & & 18.495 \\
$303 \mathrm{~K}$ & 0.036 & 0.132 & 27.778 & 0.996 & 18.225 \\
$313 \mathrm{~K}$ & 0.040 & 0.171 & 25.000 & 0.997 & 18.832 \\
$323 \mathrm{~K}$ & 0.091 & 0.189 & 10.989 & 0.966 & 17.256 \\
$333 \mathrm{~K}$ & 0.198 & 0.211 & 5.051 & 0.989 & 15.606 \\
\hline
\end{tabular}

The data from the study gave the best fit with adsorption models presented in Table 5, acknowledging that the plots gave linear slopes with regression coefficients, $\mathrm{R}^{2}$, values greater than $0.99^{29}$. Table 5 shows the parameters of linearization for each adsorption model. $\mathrm{K}_{\mathrm{ads}}$ value shows the strength between adsorbate and adsorbent. $\mathrm{K}_{\mathrm{ads}}$ high values signify greater adsorption and, hence, better inhibition efficiency and vice versa ${ }^{27}$. From Table 5, it is clear that $\mathrm{K}_{\mathrm{ads}}$ values are low, indicating weak interactions between the extract and the mild steel surface. It, therefore, suggests that an electrostatic interaction (physisorption) exists between the extract molecules and the mild steel surface ${ }^{22}$, ${ }^{27}$. It is also significant to state that the $\mathrm{K}_{\mathrm{ads}}$ value of the equilibrium constant of adsorption obtained from the intercept of the adsorption isotherm is related to the free energy of adsorption, as follows.

$$
\Delta \mathrm{G}_{\text {ads }}^{\circ}=-2.303 \mathrm{RT} \log \left(55.5 \mathrm{~K}_{\text {ads }}\right)
$$

Obtained results indicate that $\Delta \mathrm{G}_{\text {ads }}$ values are negative in all cases, showing that the reaction is spontaneous ${ }^{2,24,28,30} ; \Delta \mathrm{G}_{\text {ads }}$ values up to $-20 \mathrm{kJmol}^{-1}$ have typically been correlated with electrostatic interactions between inhibitor molecules and charged metal surface (physisorption), while those more negative than $-20 \mathrm{~kJ}$ $\mathrm{mol}^{-1}$ involve charge sharing or transfer from the inhibitor molecules to the metal surface, to form a coordinate type of bond (chemisorption) ${ }^{2,24,30}$. From Table 5, it 
can be observed that $\Delta \mathrm{G}_{\mathrm{ads}}$ evaluated values were negative $\left(<-20 \mathrm{~kJ} \mathrm{~mol}^{-1}\right)$, indicating that the extract adsorption was spontaneous and that the adsorption mechanism was physisorption.

\section{Surface analysis}

SEM images were taken, in order to study the surface morphology of the uninhibited and inhibited mild steel samples. The surface morphologies of fresh mild steel, in a solution of $0.1 \mathrm{M} \mathrm{H}_{2} \mathrm{SO}_{4}$, and in the inhibitor presence $(0.5 \mathrm{~g} / \mathrm{L})$, were studied using scanning electron microscopy. Figs. $10 \mathrm{a}, \mathrm{b}$ and $\mathrm{c}$ show the SEM micrographs of the free, uninhibited and inhibited mild steel samples.

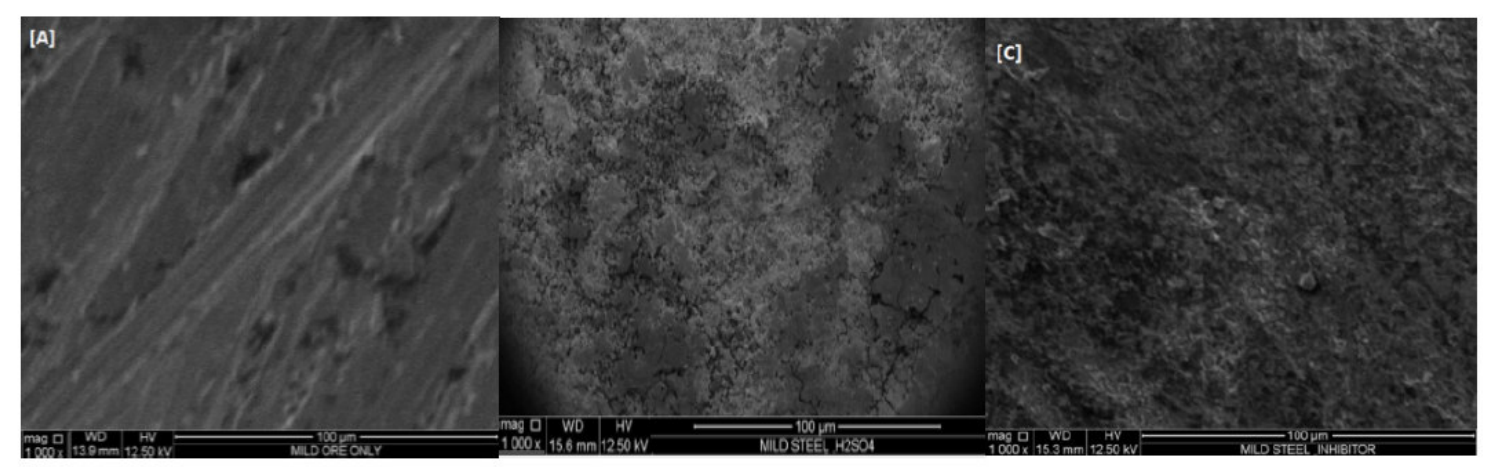

Figure 10. SEM micrographs of mild steel: (a) fresh mild steel, (b) without inhibitor; $\left(0.1 \mathrm{M} \mathrm{H}_{2} \mathrm{SO}_{4}\right)$, (c) with inhibitor.

Fig.10b shows that the mild steel surface is highly damaged, due to the effect of the acid on the surface; in Fig.10c, there was an improvement in the surface morphology, which shows a smooth surface, when compared to the uninhibited surface. It is evident that the damaging effect of the acid on the mild steel is greatly reduced, due to the protective layer of the adsorbed inhibitor, which prevents corrosion caused by the acid attack on the mild steel surface. The smoothness of the mild steel surface, in the presence of an inhibitor, is due to the barrier of the protective film over the metal surface, giving rise to more ordered corrosion products ${ }^{16}$.

\section{FTIR study}

In order to further support the adsorption behaviour of the inhibitor onto the mild steel surface, FTIR spectroscopy was employed. Fig. 11a shows the FTIR spectrum of ethanol extract of ANLE alone. Fig.11b shows the FTIR spectrum of the corrosion product, when ethanol extract of ANLE was used as an inhibitor. 

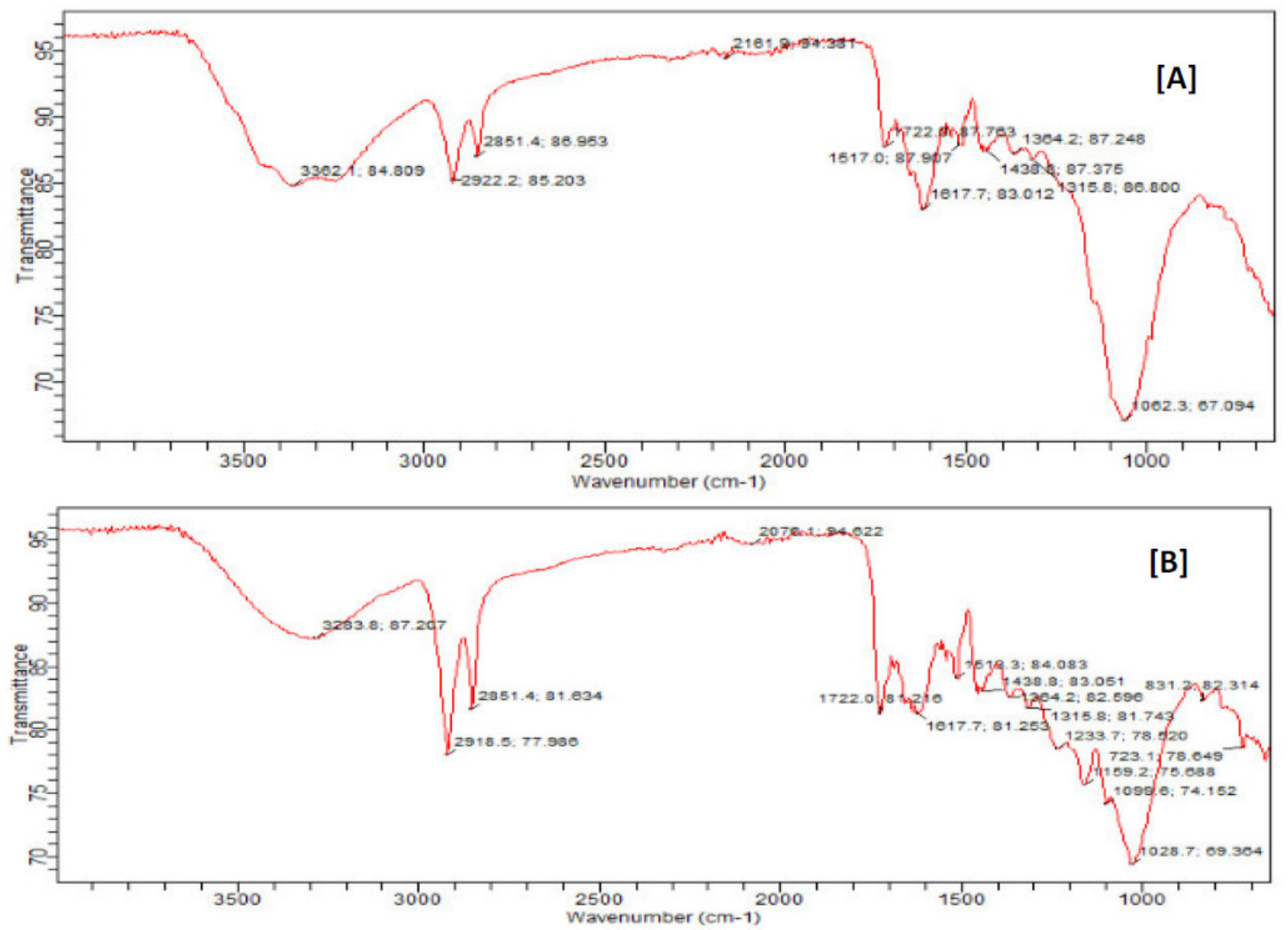

Figure 11. FTIR spectra of (a) ethanol extract of ANLE, (b) mild steel corrosion product in the inhibitor presence.

Peak and frequencies of FTIR adsorption for both spectra are presented in Table 6. From the obtained results, it is also evident that: the $\mathrm{C}-\mathrm{O}$ stretch, at 1233.7 $\mathrm{cm}^{-1}$, was shifted to $1062.3 \mathrm{~cm}^{-1}$; the $-\mathrm{C}=\mathrm{C}-\mathrm{stretch}$, at $1617.7 \mathrm{~cm}^{-1}$, was shifted to $1517.7 \mathrm{~cm}^{-1}$; the C-H (Alkene stretch), at $2918.5 \mathrm{~cm}^{-1}$, was shifted to $2851.4 \mathrm{~cm}^{-}$ 1; the aromatic $\mathrm{C}=\mathrm{O}$, at $1722.0 \mathrm{~cm}^{-1}$, was shifted to $1722.8 \mathrm{~cm}^{-1}$; the $\mathrm{N}=\mathrm{O}(\mathrm{R}-$ $\mathrm{NO}_{2}$ ), at $1518.3 \mathrm{~cm}^{-1}$, was shifted to $1384.2 \mathrm{~cm}^{-1}$; and the phenolic $-\mathrm{OH}$ stretch, at $3283.8 \mathrm{~cm}^{-1}$, was shifted to $3362.1 \mathrm{~cm}^{-1}$. These shifts in frequencies also indicate that there is an interaction between the inhibitor and the metal surface ${ }^{30,31,32}$. It is also evident from the obtained data that the $\mathrm{C}-\mathrm{O}$ stretch, at $1159.2 \mathrm{~cm}^{-1}$, as well as $\mathrm{N}=\mathrm{O}\left(\mathrm{R}-\mathrm{NO}_{2}\right)$, at $1364.2 \mathrm{~cm}^{-1}$, were missing, suggesting that these bond frequencies might have been used for bonding between the Fe vacant d-orbital and the inhibitor ${ }^{28}$. Therefore, ANLE was adsorbed onto the mild steel surface through these functional groups ${ }^{34}$. 
Table 6. Functional groups assigned to the ethanol leaves extract adsorption and to the corrosion product when the extract is used as an inhibitor.

\begin{tabular}{|c|c|l|c|c|l|}
\hline \multicolumn{3}{|c|}{ Ethanol extract } & \multicolumn{3}{c|}{ Corrosion product } \\
\hline $\begin{array}{c}\text { Wave no } \\
(\mathrm{cm}-1)\end{array}$ & Height & $\begin{array}{c}\text { Assigned functional } \\
\text { group }\end{array}$ & $\begin{array}{c}\text { Wave no } \\
(\mathrm{cm}-1)\end{array}$ & Height & $\begin{array}{c}\text { Assigned functional } \\
\text { group }\end{array}$ \\
\hline 3283.8 & 87.207 & O-H H-bonded & 3362.1 & 84.809 & O-H H-bonded \\
\hline 2918.5 & 77.986 & C-H Alkene stretch & 2851.4 & 86.953 & C-H Alkane stretch \\
\hline 2851.4 & 81.634 & C-H Alkene stretch & 2922.2 & 85.203 & C=O Aldehyde \\
\hline 1722.0 & 81.218 & C=O Aldehyde & 1722.8 & 87.783 & C=O Aldehyde \\
\hline 1617.7 & 81.253 & C=C Alkene & 1517.7 & 83.012 & C=C Alkene \\
\hline 1518.3 & 84.083 & N=O Nitro (R-NO2) & 1384.2 & 87.248 & N=O Nitro (R-NO $)^{\text {O }}$ \\
\hline 1438.8 & 83.051 & C-H -CH3(bend) & 1438.8 & 87.375 & C-H -CH3 (bend) \\
\hline 1364.2 & 82.596 & N=O Nitro (R-NO2) & - & - & - \\
\hline 1159.2 & 75.688 & C-O stretch & - & - & C-O stretch \\
\hline 1233.7 & 78.520 & C-O stretch & 1062.3 & 67.094 & - \\
\hline
\end{tabular}

\section{UV-visible study}

Fig.12 illustrates the UV-visible spectra of ethanol extract of Acacia nilotica leaves and of the solution containing washings of mild steel samples immersed in the extracts. A careful investigation of Fig.12 revealed that both spectra were similar in appearance, but had different absorption coefficient values, suggesting that the extracts organic matter was successfully adsorbed onto the metal surface. 

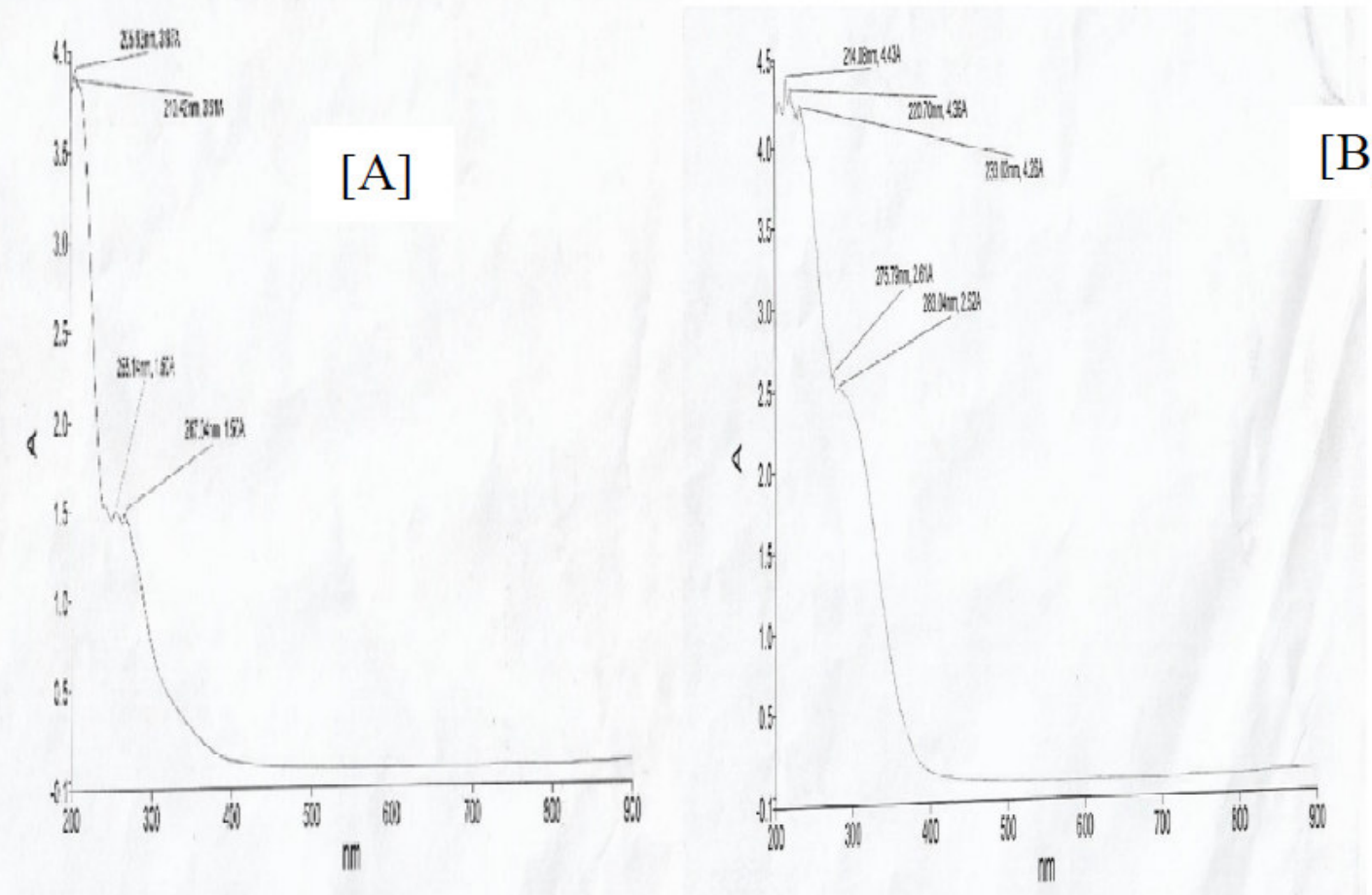

Figure 12. UV-visible spectra of (a) ANLE extracts (b) ANLE extracts molecules adsorbed onto the mild steel surface.

It is evident from Fig. $12 \mathrm{a}$ that peaks ranged from $214 \mathrm{~nm}$ to $283 \mathrm{~nm}$ in the extracts spectra, which supported the presence of tannins, alkaloids, phenols and flavonoids ${ }^{14}$. It is also obvious from Fig. $12 \mathrm{~b}$ that the wavelengths were changed with the presence of mild steel washings. This fact suggested that molecular changes occurred in the extracts constituents during corrosion, which might have happened due to the adsorption of the bioactive compounds present in the extracts. The study confirms the structural changes in the ANLE extract solution, hence confirming its inhibition properties on mild steel.

\section{HPLC analysis}

Fig.13 illustrates the HPLC chromatogram of ANLE ethanol extract. It was only made the identification of the chief constituent of the leaves extracts. In the extract, a major component was detected, at a retention time of $5.990 \mathrm{~min}$. This organic molecule was identified as Catechin (by retention time). Therefore, it could be concluded that Catechin was the main constituent of ANLE ethanol extract. 


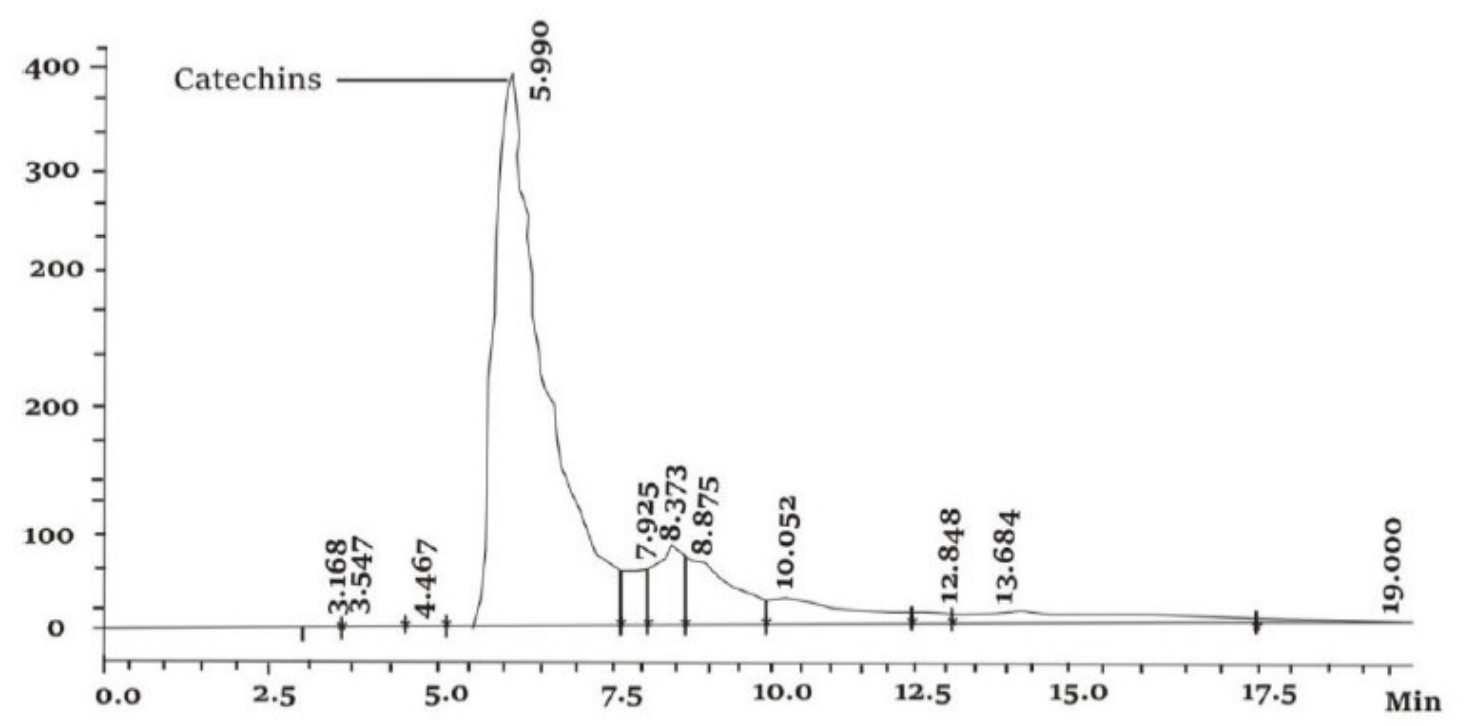

Figure 13. HPLC chromatogram of ANLE ethanol extract.

\section{Tafel polarization study}

Fig. 14 shows polarization curves obtained in the absence and presence of ANLE extracts, for mild steel in $0.1 \mathrm{M} \mathrm{H}_{2} \mathrm{SO}_{4}$, at $28^{\circ} \mathrm{C}$.

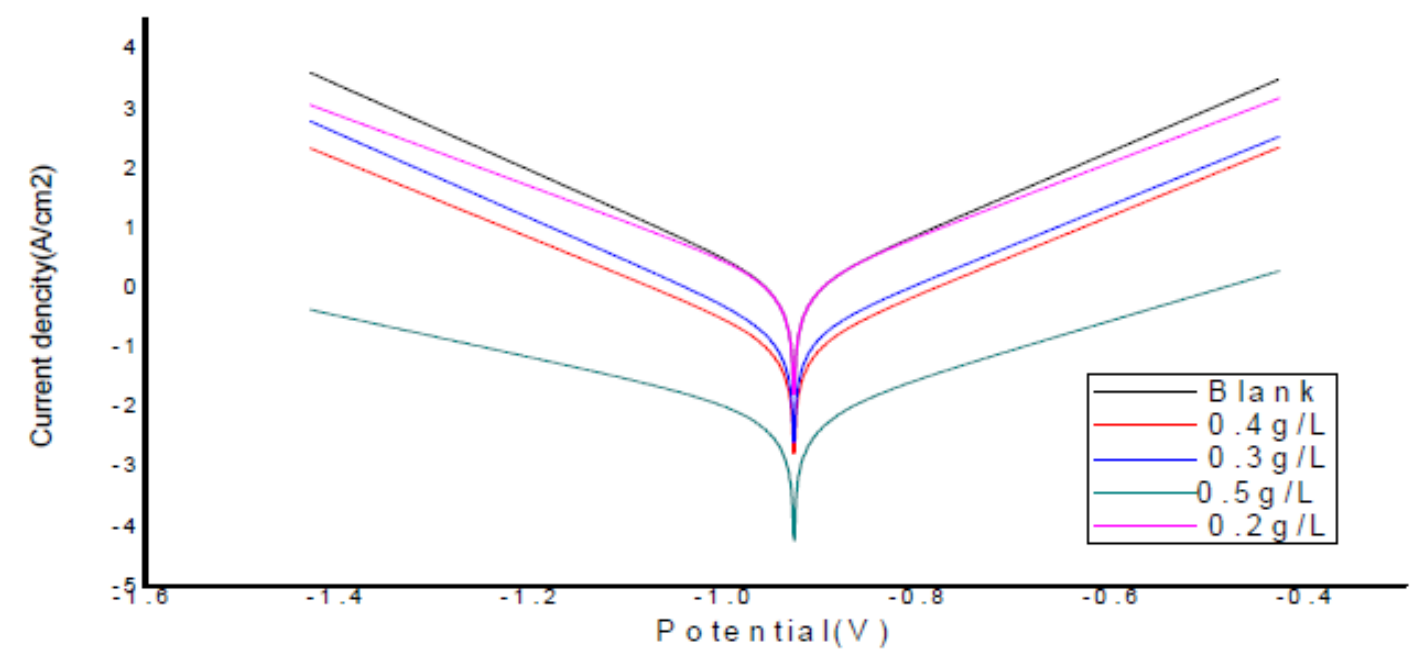

Figure 14. Tafel polarization curves for mild steel, with different concentrations of ANLE ethanol extract, in $0.1 \mathrm{M} \mathrm{H}_{2} \mathrm{SO}_{4}$.

From the polarization curves analysis, it was revealed that the equilibrium corrosion potential ( $\left.E_{\text {corr }}\right)$ vatues changed, as well as corrosion current density (Icorr) values reduced with inhibitor concentration, which elucidated that the extracts organic constituents have inhibited mild steel corrosion rate in $\mathrm{H}_{2} \mathrm{SO}_{4}$. Also, it is clear from Fig. 14 that anodic and cathodic reactions were effectively suppressed by the inhibitor addition, suggesting that ANLE extracts functioned as a mixed type inhibitor in $\mathrm{H}_{2} \mathrm{SO}_{4}$ solutions. 
Corrosion parameters, such as $E_{\text {corr }} I_{\text {corr }}$, the slope of anodic $\left(b_{a}\right)$ and cathodic $\left(b_{c}\right)$ Tafel curve and polarization resistance values were computed from Tafel polarization curves and are listed in Table 7. A careful investigation of Tafel parameters elucidated that the inhibitor addition displaced $\mathrm{E}_{\text {corr }}$ of corrosion reactions; however, the displacement in $E_{\text {corr }}$ values did not indicate any

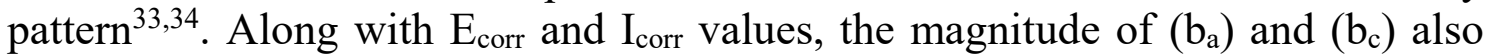
changed with the inhibitor concentration; however, the shift was not recognized to follow any trend. This fact supported the random changes occurred in $\mathrm{E}_{\text {corr }}$ values, due to the inhibitor addition.

Table 7. Tafel polarization parameters obtained at different inhibitor concentrations, for mild steel in $0.1 \mathrm{M} \mathrm{H}_{2} \mathrm{SO}_{4}$, at $28^{\circ} \mathrm{C}$.

\begin{tabular}{llllllllll}
\hline $\begin{array}{c}\text { Conc. of } \\
\text { inhibitor } \\
(\mathrm{g} / \mathrm{L})\end{array}$ & $\begin{array}{c}-\mathbf{E}_{\text {corr }} \cdot \\
(\mathrm{mV})\end{array}$ & $\begin{array}{c}\mathrm{I}_{\mathrm{ccorr}} \cdot \mathrm{X} 10^{5} \\
\left(\mathrm{~A} / \mathrm{cm}^{2}\right)\end{array}$ & $\begin{array}{c}\mathrm{b}_{\mathrm{a}} \\
(\mathrm{mV} / \mathrm{dec} .)\end{array}$ & $\begin{array}{c}-\mathrm{b}_{\mathrm{c}} \\
(\mathrm{mV} / \mathrm{dec})\end{array}$ & $\begin{array}{c}\mathrm{CR} \\
\left(\mathrm{mmyr}^{-1}\right)\end{array}$ & $\begin{array}{c}\mu \mathrm{P} \\
(\%)\end{array}$ & $\begin{array}{c}\mathrm{Rp} \\
\left(\Omega \mathrm{cm}^{2}\right)\end{array}$ & $\begin{array}{c}\mu \mathrm{PR} \\
(\%)\end{array}$ \\
\hline Blank & 790.2 & 30.12 & 3.48 & 6.80 & 3.28 & - & 18.786 & - \\
0.1 & 740.4 & 14.44 & 3.93 & 5.53 & 1.57 & 52.04 & 28.576 & 34.360 \\
0.2 & 740.7 & 12.66 & 3.73 & 5.85 & 1.37 & 58.05 & 24.823 & 24.320 \\
0.3 & 730.5 & 12.45 & 3.75 & 5.76 & 1.35 & 58.64 & 26.352 & 28.711 \\
0.4 & 730.9 & 12.44 & 3.57 & 5.74 & 1.35 & 58.69 & 26.983 & 30.380 \\
0.5 & 730.3 & 11.49 & 5.96 & 5.47 & 1.35 & 61.85 & 27.810 & 32.449 \\
\hline
\end{tabular}

Furthermore, it was analysed from Table 7 that $I_{\text {corr }}$ values diminished with an increase in the inhibitor concentration, indicating that the extracts retarded the corrosion rate of mild steel samples in $\mathrm{H}_{2} \mathrm{SO}_{4}$ solutions. Probably, the organic moieties of ANLE extract adsorbed onto the metal surface and increased the insulating behaviour of the modified mild steel electrode, which caused lowering of corrosion current values ${ }^{7,8}$. This explanation could be connected to polarization resistance values that increased with the extracts concentrations, compared to the blank, revealing that the inhibitor molecules effectively retarded the polarization process at the metal-acid interface, promoting corrosion inhibition.

\section{Conclusions}

The results obtained from the study indicate that ANLE extract effectively inhibited mild steel corrosion in $0.1 \mathrm{M} \mathrm{H}_{2} \mathrm{SO}_{4}$. Inhibition efficiency increases with higher extract concentration and immersion time and decreases with rising in temperature. The inhibition potential of this inhibitor is attributed to the presence of phenol, tannin, alkaloid and flavonoid in the extract. The adsorption characteristics of the plant extract gave the best fit with Langmuir isotherms. Obtained activation energies $\left(E_{a}\right)$ values and standard free energies of adsorption $\left(\Delta \mathrm{G}_{\text {ads }}\right)$ showed that the adsorption occurred by the physisorption mechanism, and that the adsorption process was spontaneous. In their turn, heat of adsorption 
$\left(Q_{\text {ads }}\right)$ and enthalpy of adsorption $(\Delta \mathrm{H})$ negative values obtained from the study signified that the adsorption of ANLE extract onto the mild steel surface was exothermic; hence, an increase in the reaction temperature of the medium will decrease the inhibition efficiency. In view of the above conclusion, the use of ANLE ethanol extracts as green inhibitors is recommended.

\section{Acknowledgements}

The authors are grateful to the Department of Pure and Industrial Chemistry, Bayero University Kano, for providing the necessary laboratory facilities. They are also grateful to Mr Musa Garba Beli, Engr. Mohammed Suleiman, National Geoscience Research Laboratory (NGRL), Barnawa Kaduna and National Research Institute for Chemical Technology (NARICT) Basawa Zaria, for running UV-visible, potentiodynamic polarization, SEM and metal characterization and HPLC analyses, respectively.

\section{References}

1. Abiola OK, Oforka NC, Ebenso E.E et al. Eco - Friendly Corrosion Inhibitors: Inhibitive Action of Delonix Regia Extract for the Corrosion of Aluminum in Acidic Medium. Anti Corr. Methods \&Mat. 2007;54:4:219224.

2. Ebenso, EE, Eddy NO, Odiongenyi AO. Corrosion Inhibitive Properties and Adsorption Behaviour of Ethanol Extract of Piper Guinensis as a Green Corrosion Inhibitor for Mild Steel in $\mathrm{H}_{2} \mathrm{SO}_{4}$. Afr J Pure \&Appl Chem. 2008; 2:11:107-115.

3. Bishir U, Hasmeriya M, Hassan HA, et al. Theoretical and Experimental Studies of Corrosion Inhibition of thiophen-2-ethylamine on mild steel in acid media. J Techn(Sci \& Engin).2015;76:13:7-14.

4. Ebenso EE, Isabirye DA, Eddy NO. Adsorption and quantum chemical studies on the inhibition potentials of some Thiosemicarbazides for the corrosion of mild steel acidic medium. Inter J Molec Sci. 2010;11:2473-98.

5. Obot IB, Umoren SA, Ebenso EE, et al. The Inhibition of aluminium corrosion in hydrochloric acid solution by exudate gum from Raphia hookeri. Desalination. 2009;250:225-236.

6. Oguzie EE. Inhibition of Acid Corrosion of Mild Steel by Telfaria Occidentalis Extract. Pigment and Resin Technology. 2005;34:6:321-326.

7. Oguzie EE, Enenebeaku CK., Akalezi CO. Adsorption and Corrosion Inhibiting Effect of Dacryodis Edulis Extract on Low Carbon Steel Corrosion in Acidic Media. J Colloid Interface Sci. 2010;349:283-292.

8. Oguzie EE. Studies on the inhibition effect of Occinum vivridis extract on acid corrosion of mild steel. Mat Chem \&Physics. 2006;99:2-3:441-446.

9. Oguzie EE, Adindu CB, Enenebeaku CK, et al. Natural products for materials protection: Mechanism of corrosion inhibition of mild steel by acid extracts of Piper guineense. J Phys Chem. 2012;dx.doi.org/10.1021/jp300791. 
10. Eddy NO, Odoemelam SA, Odiongenyi AO. Inhibitive, Adsorption and Synergistic Studies on Ethanol Extract of Gnetum Africana as Green Corrosion Inhibitor for Mild Steel in $\mathrm{H}_{2} \mathrm{SO}_{4}$. Green Chem Letter Review. 2009;2:2:111-119.

11. Enenebeaku CK. Electrochemical studies of the inhibitory effects of selected plant extracts on the acid corrosion of mild steel. Ph.D Thesis. Federal University of Technology. Owerri. 2011.

12. Obot IB, Obi-Egbedi NO. Fluconazole as an Inhibitor for Aluminum Corrosion in $0.1 \mathrm{M} \mathrm{HCl}$. Colloids and Surfaces A: Physicochem. Eng. Aspects. 2008;330: 207-212.

13. Momoh-Yahaya H, Eddy NO, Oguzie EE. Inhibitive, Adsorptive and Thermodynamic Study of Hypoxanthine Against the Corrosion of Aluminum and Mild Steel in Sulphuric Acid. J Mat \&Environ Sci. 2014;5:1:237-244.

14. Okafor PC, Ebenso EE. Inhibitive Action of Carica papaya Extracts on the Corrosion of Mild Steel in Acidic Media and their Adsorption Characteristics. Pigment Resin Techno. 2007;36 (3):134-140.

15. Niamien PM, Kouassi HA, Trokourey A, et al. Afr Environ Sci \& Techno. 2011;5:9:641.

16. Saedah RA. Corrosion Inhibition of Aluminum in $0.5 \mathrm{M} \mathrm{HCl}$ by Garlic Aqueous Extract. Oriental J Chem. 2014;30:2:541-552

17. Nnabuk OE, Steven AO, Anduang OO. Green Chem Letters and Reviews. 2009; Vol.2, No.2:111-119.

18. Li X, S Deng, H Fu et al. Electrochim Acta. 2009;54:4089.

19. Rajappa SK, Venkatatesha TV, Praveen BM. Bull of Mater Sci. 2008;31:1:37- 41

20. Atkin P. Physical Chemistry, 7th ed. Oxford Press. Oxford. 2002.

21. Olasehinde EF, Olusegun SJ, Adesina AS, et al. Inhibitory Action of Nicotiana Tabacum Extracts on the Corrosion of Mild Steel in $\mathrm{HCl}$ : Adsorption and Thermodynamics Study. Nat and Sci. 2013;10:12:21-34.

22. Momoh-Yahaya H, Eddy NO, Iyun JF, et al. Inhibitive and Adsorptive Behaviour of Guanine on Corrosion of Mild Steel in $0.1 \mathrm{M} \mathrm{HCl}$ and $\mathrm{H}_{2} \mathrm{SO}_{4}$. Int J Modern Chem. 2012;2:3:127-142.

23. Adeyemi OO, Olubomehin OO. Investigation of Anthocleista Djalonensis Stem Bark Extract as Corrosion Inhibitor for Aluminum. Pacific J Sci \& Techno. 2010; 11:455-461.

24. Eddy NO, Ebenso EE. Corrosion Inhibition and Adsorption Properties of Ethanol Extract of Gongronema Latifoliumon on Mild Steel in $\mathrm{H}_{2} \mathrm{SO}_{4}$. Pigment and Resin Techno. 2010;39:2:77-83.

25. Eddy NO, Odiongenyi AO. Corrosion Inhibition and Adsorption Properties of Ethanol Extract of Heinsia Crinata on Mild Steel in $\mathrm{H}_{2} \mathrm{SO}_{4}$. Pigment and Resin Techno. 2010;39:5:288-295.

26. Ismail M, Abdulrahman AS, Hussain MS. Solid Waste as Environmental Benign Corrosion Inhibitors in Acid Medium. Inter J Engin, Sci \& Techno. 2013;:2: 1742-1748. 
27. Obot IB, Obi-Egbedi NO. Adsorption Properties and Inhibition of Mild Steel Corrosion in Sulphuric Acid Solution by Ketoconazole: Experimental and Theoretical Investigation. Corr Sci. 2010;52:198-204.

28. Okoro SO, Kawo AH, Arzai AH. Phytochemical Screening, Antibacterial and Toxicological Activities of Acacia nilotica Extracts. Bayero. J Pure and Appl Sci. 2014;7(1):105-115.

29. Quraishi MA, Singh AK. Piroxicam: A Novel Corrosion Inhibitor for Mild Steel Corrosion in $\mathrm{HCl}$ Acid Solution. J Mat \& Environ. Sci. 2010;1:2:101110.

30. Eddy NO. Ethanol extract of Phyllanthus amarus as a green inhibitor for the corrosion of mild Steel in $\mathrm{H}_{2} \mathrm{SO}_{4}$. Port Electrochim Acta. 2009a; 27:5:579589.

31. Eddy NO, Ekwumengbo PA, Mamza PAP. Ethanol extract of Terminalia catappa as a green inhibitor for the corrosion of mild steel in $\mathrm{H}_{2} \mathrm{SO}_{4}$. Green Chem Letters and Review. 2009a;2:4:223-231.

32. Eddy NO, Ibok UJ, Ebenso EE. Adsorption, synergistic inhibitive effect and quantum chemical studies on ampicillin and halides for the corrosion of mild Steel, J Appl Electrochem. 2009b.DOI: 10.1007/s10800-009-0015- z.

33. Ferreira ES, Giancomelli C, Giancomelli FC, et al. Evaluation of inhibitor effect of ascorbic acid on the corrosion of mild steel. Mat Chem \&Physics. 2004;83: 129-134.

34. Saratha R, Priya SV, Thilagavathy P. Investigation of Citrus Aurantiifolia Leaves Extract as Corrosion Inhibitor for Mild Steel in $1 \mathrm{M} \mathrm{HCl}$. Electrochem J Chem. 2009;6:3:785-795.

35. Eddy ON, Femi A. Experimental and Quantum Chemical Studies on Ethanol Extract of Phyllantus amarus(EEPA) as a Green Corrosion Inhibitor for Aluminum in 1M HCl. Port Electrochim Acta. 2018;36:4:231-247. 